\title{
Comparison of Selected Anatomical and Treatment-related Diagnostic Parameters Estimated by Cone-Beam Computed Tomography and Digital Periapical Radiography in Teeth with Apical Periodontitis
}

\author{
Jelena Gudac ${ }^{1}$, Kristina Hellén-Halme ${ }^{2}$, Tadas Venskutonis ${ }^{1}$, Algirdas Puisys ${ }^{3}$, Vita Machiulskiene ${ }^{1}$ \\ ${ }^{1}$ Clinic of Dental and Oral Pathology, Lithuanian University of Health Sciences, Kaunas, Lithuania. \\ ${ }^{2}$ Department of Oral and Maxillofacial Radiology, Faculty of Odontology, Malmo University, Malmo, Sweden. \\ ${ }^{3}$ Vilnius Implantology Center clinic, Vilnius, Lithuania.
}

\author{
Corresponding Author: \\ Jelena Gudac \\ Clinic of Dental and Oral Pathology \\ Lithuanian University of Health Sciences \\ Eiveniu st. 2, LT-50009, Kaunas \\ Lithuania \\ Phone: +37061296384 \\ E-mail: jelenagudac@gmail.com
}

\begin{abstract}
Objectives: To compare selected anatomical and treatment-related diagnostic parameters estimated by cone-beam computed tomography and by digital periapical radiography in teeth with apical periodontitis, and to evaluate reliability of different examiners in interpretation of images obtained by both methods.

Material and Methods: Teeth with apical periodontitis were evaluated independently by 2 endodontists and 1 radiologist based on 128 cone-beam computed tomography (CBCT) and 162 digital periapical radiography (DPR) images. Anatomical (size, relation with root, location of periapical radiolucency) and treatment-related (canal obturation length, homogeneity, coronal seal) parameters were assessed. Fleiss kappa reflected inter-observer agreement while intra-examiner agreement was estimated by Cohen's kappa. McNemar and McNemar-Bowker tests served for evaluation of differences between CBCT- and DPR-based estimates.

Results: Cohen's kappa ranged from 0.62 to 1 for all examiners. Fleiss kappa values were nearly perfect for majority of parameters. Diagnostic discrepancy between methods was found for size of radiolucency that in $15-17 \%$ cases was larger, and in $25-28 \%$ smaller in DPR than in CBCT images. DPR revealed 20\% of root canals scored as non-obturated while in CBCT - obturation present. Canal obturation was rated as homogenous by CBCT, while absent or non-homogenous by DPR, in $17-23 \%$, and $11-14 \%$ of cases, respectively. Radiologist detected more root perforations in CBCT than in DPR images. Conclusions: Good intra- and inter-examiner agreement for anatomical and treatment-related diagnostic parameters was achieved using cone-beam computed tomography and digital periapical radiography methods and demonstrated similar diagnostic capability, although variation regarding root perforations and canal obturation quality was observed.
\end{abstract}

Keywords: cone-beam computed tomography; digital radiography; periapical periodontitis.

Accepted for publication: 4 June 2020

To cite this article:

Gudac J, Hellén-Halme K, Venskutonis T, Puisys A, Machiulskiene V.

Comparison of Selected Anatomical and Treatment-related Diagnostic Parameters Estimated by Cone-Beam Computed Tomography and Digital Periapical Radiography in Teeth with Apical Periodontitis

J Oral Maxillofac Res 2020;11(2):e4

URL: http://www.ejomr.org/JOMR/archives/2020/2/e4/v11n2e4.pdf

doi: $\underline{10.5037 / j o m r .2020 .11204}$ 


\section{INTRODUCTION}

Radiological examination of patients with presumed periapical pathology is an accepted diagnostic method to confirm the presence of the periapical diseases [1-3]. The radiographic evaluation of the periapical structures, along with evaluation of the clinical findings, serves as a basis for disease diagnosis, treatment planning as well as for the assessment of treatment outcomes.

The digital periapical radiographic (DPR) imaging has been accepted in clinical practice for nearly thirty years, and has become a routine diagnostic procedure in endodontics. However, due to the limited ability to provide a detailed view of the three-dimensional anatomical structures, DPR is often claimed to give lack of information about the important parameters such as alveolar bone thickness, root canal anatomy, size, extension and location of periapical lesions [4]. To overcome this limitation a number of other radiographic examination methods became available [5]. Particularly, the cone-beam computed tomography (CBCT) has been considered as a substantial step towards the improved pre- and postoperative diagnosis in Endodontics []. The CBCT imaging reconstructs a three-dimensional view of the maxillofacial region that allows evaluating the teeth or the area of interest in any plane [7]. Moreover, there are no problems with superimposition of structures, and it is possible to observe each root separately [ $\underline{8}]$. Thus, the CBCT has been claimed to ease detection of extra canals, vertical root fractures, post-treatment periapical lesions, and differentiation between nonendodontic and endodontic signs and symptoms [?].

An important limitation of the CBCT is the patient's exposure to high radiation doses that vary a lot, depending on a number of factors such as field of view, the desired image resolution, X-ray beam energy, filtration, exposure time, receptor technology, even the patient's size and age $[10,11]$. Due to this limitation, CBCT is recommended for use only in cases when the benefits to the patient outweigh any potential risks of the additional radiation exposure [12].

Despite the large number of studies focused on the comparison of the efficacy of different radiological methods in endodontic diagnosis, a comprehensive analysis of different anatomical and treatment-related parameters potentially having a prognostic value for the teeth subjected to root canal treatment has not been found in the literature. Moreover, the potential differences in diagnostic ability of DPR and of CBCT may influence the clinical decisions in treatment planning $[13,3]$. It is clear that both diagnostic methods are based on a subjective evaluation of the examiner thus are prone to a certain degree of misdiagnosis.

The aim of this study was to compare the estimates of selected anatomical and treatment-related parameters obtained from the cone-beam computed tomography and the digital periapical radiographic images in teeth with apical periodontitis, and to evaluate the reliability of different examiners in the interpretation of the images obtained by both methods.

\section{MATERIAL AND METHODS Sample selection}

The data were obtained from the patients participating in a large clinical trial aiming to assess the selected anatomical and treatment-related parameters in teeth with apical periodontitis (AP) based on CBCT and DPR. All patients were examined clinically and radiographically (CBCT and DPR) in the dental clinic (Vilnius Implantology Centre clinic, Vilnius, Lithuania) and were scheduled for endodontic treatment from December 2016 to December 2018. All the participants gave written informed consent to be involved in the study. The study protocol was approved by the Ethical Committee of Biomedical studies, Lithuania (Protocol No 111; edition No BE2-27).

The study participants were adult patients aging 46 (SD 12.3) years-old (range 18 to 70 yearsold) referred for the endodontic treatment with a specialist. Patients with at least one tooth with apical periodontitis (AP) (periapical changes radiographically detected associated with necrotic pulp or root filled teeth), sufficient periodontal support, primary and retreatment root canal treatment cases were included in the study. Patients had baseline CBCT images performed for general treatment planning purposes no earlier than one month prior to treatment. Both primary and retreatment cases were included. Pregnant women, immunosuppressed patients, and patients presenting with un-restorable teeth (e.g., deep root caries lesion, root fracture) or, with probing depths $>5 \mathrm{~mm}$ around the marginal bone were excluded.

A total of 128 CBCT and 162 DPR images of 176 teeth were obtained from 128 patients who fulfilled the above described inclusion criteria and agreed to participate.

The time interval between $\mathrm{CBCT}$ and DPR examinations was no more than 1 month. 


\section{Radiographic examinations CBCT imaging}

The images were obtained with i-CAT scanner (Imaging Sciences International Inc., Hatfield, PA, USA); exposure parameters: $84 \mathrm{kV}, 5 \mathrm{~mA}, 0.3 \mathrm{~mm}$ voxel resolution, $6 \times 16 \mathrm{~cm}$ field of view, $18.3 \mathrm{sec}$ acquisition time. All the obtained images were examined on the 27-inch flat panel display computer screen (Apple, MacBook Pro, USA) with a pixel resolution of $2,560 \times 1,440$, in a dimmed room without time restrictions for the evaluations. The $\mathrm{CBCT}$ images were evaluated using the original viewing program from i-CAT viewing software (Imaging Sciences International, Inc., Hatfield, PA, USA). The images that best confirmed presence or absence of a periapical lesion in the sagittal, coronal and/or axial planes were used. The filters were set to normal, and only brightness and contrast were adjusted.

\section{DPR imaging}

Straight projection intraoral periapical radiographs were obtained using the digital imaging system Kodak (Carestream Dental LLC, Atlanta, GA, USA) with a parallel technique (exposure parameters - 60 $\mathrm{kV}, 7 \mathrm{~mA}$ and $0.3 \mathrm{sec}$ ). The images were captured and fixed using a sensor holder. A protractor was used to accurately angulate the X-ray beam for the parallel images $[\underline{14}, \underline{15}]$. The teeth were aligned with the $90^{\circ}$ line on the protractor, which was centred on the X-ray tube. The DPR images were viewed as an original Kodak dental imaging presentation (Apple, Cupertino, CA, USA). Each examiner was allowed to adjust on the image brightness and contrast.

\section{Imaging analysis}

All the obtained CBCT and DPR images were evaluated independently by 3 examiners with clinical experience using DPR and CBCT techniques and without knowledge of the clinical outcomes:

- I and II - qualified endodontists;

- III - oral and maxillofacial radiologist.

Prior to evaluation, the examiners were trained using examples of both techniques. Thus, $30 \mathrm{CBCT}$ and 30 DPR images were used for discussion. All cases of disagreement were debated until a consensus was reached. The parameters assessed by three examiners from the DPR and CBCT images were adopted from Venskutonis et al. [16] as described in Table 1.

\section{Intra- and inter-examiner reliability}

The intra-examiner reliability assessment of CBCT and of DPR scorings was performed for each examiner on the basis of $30 \mathrm{DPR}$ and $30 \mathrm{CBCT}$ images of the randomly selected cases from the clinical study that had been scored independently twice, within a month period. The inter-observer reliability assessment as well as comparison of the diagnostic capability of two radiographic methods (CBCT and DPR) was performed on the basis of all 128 CBCT and 162 DPR images that had been evaluated independently by all three examiners.

\section{Statistical analysis}

Sample size calculation was performed following the protocol of the clinical trial, and was based on the data from the clinical study reported by Patel et al. [17]. For the purpose of data analysis, the scores S0 were considered as "periapical lesion absent" ("no"), while the scores S1, S2 and S3 implied the periapical lesion "present" ("yes"). The scorings of canal obturation length were defined accordingly: L0 equivalent to "no obturation material" ("no") whereas L1, L2, L3, L4 were equivalent to obturation material present ("yes"). CS0 scores were defined as "no seal" ("no"), and CS1, CS2 comprised the score for "seal present" ("yes").

The Cohen's kappa was used to assess intra-observer agreement while Fleiss kappa analysis was used to assess the inter-observer agreements of all 3 observers on each variable. The calculations were done separately for CBCT and DPR. The frequency distributions of all the parameters were obtained. The descriptive statistics was used to illustrate the numbers of root canals identified by three examiners. Comparison of the results obtained by CBCT and DPR was performed using McNemar and McNemarBowker tests. Significance level was set at $\mathrm{P} \leq 0.05$ and the $95 \%$ confidence interval (CI) [18]. The data analyses were performed using SPSS statistical software (version 19.0, SPSS Inc., Chicago, Illinois, USA).

\section{RESULTS \\ Intra- and inter-examiner reliability}

The intra-examiner agreement estimates of three examiners varied from substantial to perfect, irrespective of which examination method (CBCT or DPR) was used. Thus, the Cohen's kappa values for examiner I ranged from 0.84 to 1 and from 0.83 to 1 , 
Table 1. Assessment criteria of anatomical and treatment-related parameters adapted from Venskutonis et al. [17]

\begin{tabular}{|c|c|}
\hline Parameters & Severity criteria \\
\hline \multicolumn{2}{|l|}{ Anatomical } \\
\hline Size of periapical radiolucency ${ }^{\mathrm{a}}(\mathrm{S})$ & $\begin{array}{l}\text { S0: radiolucency does not exceed } 2 \text { times the width of the lateral periodontal ligament space; } \\
\text { S1: diameter of well-defined radiolucency up to } 3 \mathrm{~mm} \text {; } \\
\text { S2: diameter of well-defined radiolucency } 3: 5 \mathrm{~mm} \text {; } \\
\text { S3: diameter of well-defined radiolucency }>5 \mathrm{~mm}\end{array}$ \\
\hline $\begin{array}{l}\text { Relationship between dental root and } \\
\text { periapical radiolucency }(\mathrm{R})\end{array}$ & $\begin{array}{l}\text { R1: radiolucency appears on one root; } \\
\text { R2: radiolucency appears on more than one root; } \\
\text { R3: radiolucency involves furcation area }\end{array}$ \\
\hline $\begin{array}{l}\text { Location of radiographically detected } \\
\text { bone destruction (D) }\end{array}$ & $\begin{array}{l}\text { D1: radiolucency around root apex; } \\
\text { D2: radiolucency is in contact with important anatomical structures; } \\
\text { D3: destruction of cortical bone }\end{array}$ \\
\hline \multicolumn{2}{|l|}{ Treatment-related } \\
\hline Canal obturation length (L) & $\begin{array}{l}\text { L0: no obturation material radiographically visible in pulp chamber and in root canal space; } \\
\text { L1: obturation material visible in root canal space, } 0: 2 \mathrm{~mm} \text { from radiographic root apex; } \\
\text { L2: obturation material visible in root canal space, }>2 \mathrm{~mm} \text { from radiographic root apex; } \\
\text { L3: extrusion of obturation material through root apex; } \\
\text { L4: obturation material radiographically visible only in pulp chamber }\end{array}$ \\
\hline Obturation homogeneity $(\mathrm{H})$ & $\begin{array}{l}\text { H0: no obturation material radiographically visible in root canal; } \\
\text { H1: homogenous appearance of obturation material in root canal space; } \\
\text { H2: voids and porosity of obturation material in root canal space }\end{array}$ \\
\hline Coronal seal (CS) & $\begin{array}{l}\text { CS0: no coronal restoration; } \\
\text { CS1: adequate/coronal restoration appears intact radiographically; } \\
\text { CS2: inadequate (detectable radiographic signs of overhangs, open margins, recurrent caries, } \\
\text { or lost coronal restoration) }\end{array}$ \\
\hline $\begin{array}{l}\text { Presence of complications/failures } \\
\text { (root perforation, untreated/missed } \\
\text { root canal, root resorption, root/tooth } \\
\text { fracture, endodontically treated root } \\
\text { with radiolucency, instrument fracture } \\
\text { in root canal) (CF) }\end{array}$ & $\begin{array}{l}\text { CF0: no; } \\
\text { CF1: yes }\end{array}$ \\
\hline Post inside root canal $(\mathrm{P})$ & $\begin{array}{l}\text { P0: no; } \\
\text { P1: yes }\end{array}$ \\
\hline
\end{tabular}

aPeriapical lesion on the digital periapical radiography was defined as a radiolucency located in the periapical area of the tooth in connection with the apical part of the root exceeding at least twice the width of the periodontal ligament space [5].

For the cone-beam computed tomography images, the same criterion was applied, and the radiolucency had to be visible at least in two image planes.

while for examiner II were 0.73 to 1 and from 0.62 to 1 and, for examiner III, from 0.66 to 1 and from 0.92 to 1 , for CBCT and DPR readings, respectively.

The results of the inter-examiner agreement between three examiners using two examination methods are presented in Table 2. The perfect inter-examiner agreement (Fleiss kappa equal to 1) was observed regarding the parameters such as coronal seal (yes/ no), root canal not treated/missed, root resorption, root/tooth fracture, instrument fracture, for both CBCT and DPR methods of analysis. For the other assessed parameters the inter-agreement was almost perfect [19]. The exception was assessment of root perforations from the $\mathrm{CBCT}$ images that resulted with high divergence among the examiners and subsequently, with very low kappa value (Table 2).

\section{Comparison of the study parameters evaluated by DPR and CBCT}

Table 3 describes the counts of the identified root canals with respect to the examination method, and to the examiner. Thus, the endodontists observed a total of 403 and 395 canals using CBCT and DPR, respectively. The respective counts identified by the radiologist were 405 (CBCT) and 403 (DPR). The discrepancies in the counts were related to identification of the root canals in the premolars and molars (Table 3).

When the observations of the study parameters obtained by CBCT and by DPR were compared, the majority of the scorings did not differ between the methods, for all the examiners (Table 4). 
Table 2. Inter-examiner agreement (Fleiss kappa values, and 95\% confidence intervals [CI]) for CBCT and DPR

\begin{tabular}{l|c|c}
\hline \multirow{2}{*}{ Periapical lesion (yes/no) } & CBCT & DPR \\
\cline { 2 - 3 } & Kappa (95\% CI) & Kappa (95\% CI) \\
\hline Size of periapical radiolucency & $0.955(0.928 ; 0.977)$ & $0.904(0.863 ; 0.938)$ \\
\hline Relationship between root and radiolucency & $0.962(0.937 ; 0.983)$ & $0.906(0.87 ; 0.937)$ \\
\hline Location of bone destruction & $0.966(0.939 ; 0.985)$ & $0.911(0.874 ; 0.942)$ \\
\hline Root canal obturation (yes/no) & $0.987(0.954 ; 1)$ & $0.967(0.918 ; 1)$ \\
\hline Obturation length, mm & $0.982(0.966 ; 0.992)$ & $0.96(0.937 ; 0.977)$ \\
\hline Obturation homogeneity & $0.982(0.961 ; 0.993)$ & $0.928(0.895 ; 0.956)$ \\
\hline Coronal seal (yes/no) & 1 & 1 \\
\hline Coronal seal (adequate/inadequate) & $0.913(0.866 ; 0.949)$ & $0.763(0.693 ; 0.827)$ \\
\hline Complications (yes/no) & $0.96(0.935 ; 0.981)$ & $0.833(0.782 ; 0.874)$ \\
\hline Root perforation & $0.189(-0.021 ; 0.401)$ & 1 \\
\hline Root canal not treated/missed & 1 & 1 \\
\hline Root resorption & 1 & 1 \\
\hline Root/tooth fracture & 1 & 1 \\
\hline Endodontically treated root with radiolucency & $0.969(0.946 ; 0.989)$ & $0.888(0.844 ; 0.926)$ \\
\hline Instrument fractures & 1 & 1 \\
\hline Post inside the root canal & $0.938(0.865 ; 0.987)$ & $0.951(0.876 ; 1)$ \\
\hline & &
\end{tabular}

Fleiss kappa (statistically significant at the level $\mathrm{P} \leq 0.05$ ).

$\mathrm{CBCT}=$ cone-beam computed tomography; $\mathrm{DPR}=$ digital periapical radiography .

Table 3. Counts of observed root canals in teeth with apical periodontitis, by examination method

\begin{tabular}{l|c|c|c|c|c|c}
\hline \multirow{2}{*}{$\begin{array}{c}\text { Types of } \\
\text { root canals }\end{array}$} & \multicolumn{3}{c|}{$\begin{array}{c}\text { CBCT observed } \\
\text { cants (n) of root } \\
\text { by examiner }\end{array}$} & \multicolumn{3}{c}{$\begin{array}{c}\text { DPR observed } \\
\text { counts (n) of root } \\
\text { canals, } \\
\text { by examiner }\end{array}$} \\
\cline { 2 - 7 } & I & II & III & I & II & III \\
\hline 1 canal/per root & 59 & 59 & 57 & 64 & 64 & 56 \\
\hline MB1 canal & 81 & 81 & 81 & 81 & 81 & 81 \\
\hline MB2 canal & 18 & 18 & 18 & 18 & 18 & 18 \\
\hline ML canal & 29 & 29 & 29 & 28 & 28 & 28 \\
\hline DB canal & 61 & 61 & 60 & 60 & 60 & 61 \\
\hline DL canal & 12 & 12 & 12 & 10 & 10 & 12 \\
\hline Distal canal & 27 & 27 & 27 & 28 & 28 & 26 \\
\hline Buccal canal & 36 & 36 & 39 & 31 & 31 & 39 \\
\hline Palatal canal & 72 & 72 & 73 & 70 & 70 & 74 \\
\hline Lingual canal & 8 & 8 & 9 & 5 & 5 & 8 \\
\hline Total & 403 & 403 & 405 & 395 & 395 & 403 \\
\hline
\end{tabular}

$\mathrm{n}=$ number of observed cases with the respective type of root canal.

$\mathrm{CBCT}=$ cone-beam computed tomography; $\mathrm{DPR}=$ digital periapical radiography.
Table 4. The P-values for the estimated differences in the observations obtained by DPR and CBCT, by three examiners

\begin{tabular}{l|c|c|c}
\hline \multirow{2}{*}{\multicolumn{1}{c|}{ Variables }} & \multicolumn{3}{c}{ P-value } \\
\cline { 2 - 4 } & \multicolumn{3}{c}{ Examiners } \\
\cline { 2 - 4 } & 0.109 & 0.201 & 0.165 \\
\hline Periapical lesion (yes/no) $^{\mathrm{a}}$ & 0.001 & 0.002 & 0.002 \\
\hline Size of radiolucency $^{\mathrm{b}}$ & 0.389 & 0.4 & 0.132 \\
\hline $\begin{array}{l}\text { Relationship between root and } \\
\text { radiolucency }\end{array}$ & 0.112 & 0.199 & 0.138 \\
\hline Location of bone destruction $^{\mathrm{b}}$ & 0.125 & 0.227 & 0.039 \\
\hline Presence of root canal obturation (yes/no) $^{\mathrm{a}}$ & 0.361 & 0.167 & 0.222 \\
\hline Obturation length, mm $^{\mathrm{b}}$ & 0.168 & 0.015 & 0.21 \\
\hline Obturation homogeneity $^{\mathrm{b}}$ & 1 & 1 & 1 \\
\hline Coronal seal (yes/no) $^{\mathrm{a}}$ & 0.394 & 0.182 & 0.853 \\
\hline Coronal seal (adequate/inadequate) $^{\mathrm{b}}$ & 0.62 & 0.91 & 0.712 \\
\hline Presence of complications/failures $^{\mathrm{a}}$ & 0.5 & 0.625 & 0.0001 \\
\hline Root perforation $^{\mathrm{a}}$ & 0.275 & 0.254 & 0.089 \\
\hline $\begin{array}{l}\text { Endodontically treated root with } \\
\text { radiolucency }^{\mathrm{a}}\end{array}$ & 0.25 & 0.25 & 0.25 \\
\hline Instrument fractures $^{\mathrm{a}}$ & 1 & 0.739 & 0.739 \\
\hline Post inside the root canal $^{\mathrm{a}}$ & \multicolumn{2}{|c}{} \\
\hline
\end{tabular}

${ }^{\mathrm{a}} \mathrm{McNemar}$ test (statistically significant at the level $\mathrm{P} \leq 0.05$ );

${ }^{b} \mathrm{McNemar}-B o w k e r$ test (statistically significant at the level $\mathrm{P} \leq 0.05$ ). $\mathrm{DPR}=$ digital periapical radiography; $\mathrm{CBCT}=$ cone-beam computed tomography. 
Table 5. Distribution of scores for size of radiolucency, between CBCT and DPR, related to examiners I, II and III

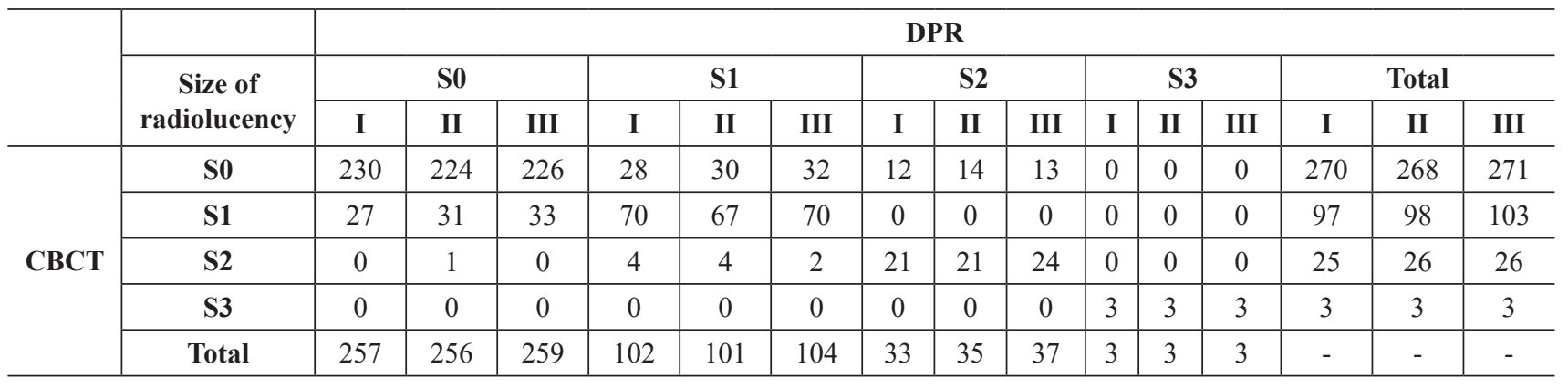

$\mathrm{DPR}=$ digital periapical radiography $\mathrm{CBCT}=$ cone-beam computed tomography.

However, all three examiners differed in their judgement of size of radiolucency that in $15-17 \%$ cases had been scored larger and, in 25 to $28 \%$ cases, smaller on DPR than on CBCT images (Table 5). However, only S0 scores (no periapical lesion) were rated as more severe (lesion present, S1 or S2) in DPR images, whereas the other non-matching lesion ratings were scored as more severe by means of CBCT, by all three examiners. Furthermore, in $10-13 \%$ of the cases the DPR score S0 was interpreted as S1 on the CBCT images (Table 5).

Analysis of the treatment-related parameters showed that in $19-24 \%$ cases the root canals had been scored by all three examiners as non-obturated (L0) by DPR, however, had a record of obturation material visible in $\mathrm{CBCT}$ images. The difference reached the significance level for examiner III. Furthermore, the differences were found for obturation homogeneity such that $17,19,23 \%$ of cases (examiners I, II, III) had been rated by $\mathrm{CBCT}$ as $\mathrm{H} 1$ (homogenous), but by DPR - as H0 (no obturation). In $11,13,14 \%$ of cases the DPR scores were $\mathrm{H} 2$ (non-homogenous), in contrast to the CBCT scores (H1), as reported by the examiners I, II and III, respectively. Conversely, the CBCT images in $16,19,24 \%$ of cases were rated $\mathrm{H} 2$ while they were seen as homogenous (H1) on the DPR images, by three examiners.

A statistically significant difference in the number of root perforations observed by means of $\mathrm{CBCT}$, was estimated for one examiner (III), the radiologist. Thus, this examiner recorded 25 canals with root perforation present in the CBCT images, but only one case was visible in DPR images. The majority of the recorded root perforations were in molars.

\section{DISCUSSION}

The present results showed that the majority of the diagnostic parameters used in this study could be evaluated reliably by both examination methods.
Thus, analysis of the anatomical parameters (presence, size, location of the periapical radiolucency) and of the important treatment-related parameters such as root canal obturation length, homogeneity and coronal seal, confirmed that the recordings could be reproduced by the same examiner or by another examiner to the extent of almost perfect agreement, either using DPR or CBCT technique. Most likely, the high level of reproducibility of the recordings was achieved by the extensive training of the examiners prior to the study. Furthermore, a detailed description of the scoring criteria facilitated communication and understanding between the different specialists and a substantial agreement in the scorings. As reported previously, the diagnostic capability of the radiographic images may vary depending on the clinical experience of the examiners as well as on their education [20]. Accordingly, previous studies also reported intra- and inter-observer agreement values being good or very good [21].

Comparison of the diagnostic capability of two radiographic methods based on the total study sample revealed that the majority of the scorings of different study parameters provided by three examiners were comparable between the methods. However, all the examiners identified more root canals using CBCT than DPR. The root canal counts mostly differed in the premolars and molars, the variations attributed particularly to the lingual and buccal canals. These findings are in agreement with the results of other studies $[22,23]$.

In contrast to the common belief that $\mathrm{CBCT}$ is able to detect significantly more periapical lesions [24], our data showed no differences between two radiographic examination methods with regard to the lesion presence. However, the estimates of the periapical lesion size (size of radiolucency) differed statistically significantly for all the examiners, when the CBCT and DPR images had been compared. In $25-28 \%$ of the cases the periapical lesions appeared larger on the CBCT images, thus supporting the notion that 
two-dimensional digital modalities may underestimate the real extent of the lesions and sometimes suffer from superimposition of various anatomic structures. However, when differentiating the very early lesions (S1) from the status defined as no pathology (S0), the variation magnitude between the scores obtained from two radiographic images was very similar and constituted $10-13 \%$ of all cases. Although the conclusion from an earlier study supported by histological validation stated that DPR had lower sensitivity than CBCT, particularly with regard to small periapical lesions, it is obvious that both methods are based on a subjective judgement of the examiners, and potentially may present with a certain number of false positives [25]. The design of the present study did not allow for histological validation of the diagnoses, however, the obtained results indicated presence of difficulties in discrimination of the early stages of the periapical pathology, regardless of the radiographic examination method employed. Since the presence of the radiographically detected periapical lesion has a significant impact on the following treatment decisions, it is clear that both, the CBCT, and the DPR techniques, taken alone, cannot be used for the endodontic diagnosis, without careful evaluation of the clinical symptoms.

For one examiner, statistically significant difference between two methods of radiographic diagnosis was estimated for the number of identified root perforations. The radiologist recorded 25 cases with root perforation present on the CBCT images that had been missed by DPR. Comparison of the recordings provided by the other two examiners (endodontists) did not reach the significant difference. Such variation in the recordings could be explained by the finding that both methods have low sensitivity to diagnose root perforations. The potential problem with DPR images is that the two-dimensional projection may not be able to identify perforations hidden due to the anatomical concavity of the root. As concerns the CBCT technique, Shemesh et al. [26] suggested that presence of radiopaque artefacts in CBCT images could lead to misdiagnosis of the root perforation. The artefacts may arise as a result of unit-related (scatter, aliasing, and unit-motion) as well as patient-related e.g., motion factors. They can appear as stripe or, ring-like patterns, double bone contours, and result in overall lack of sharpness [27]. Even though it is suggested that diagnostic accuracy of CBCT scans is generally higher, the present results are in agreement with the above discussed in vitro findings that's both imaging techniques are not able to reliably detect root perforations. Unfortunately, the low frequency of failures/complications in the study sample does not allow for a definite conclusion regarding the accuracy of scoring the root perforations. However, high risk of diagnostic error for CBCT identified root perforations has been recognized by other researchers as well $[\underline{26}, \underline{28}]$.

Two earlier studies reported that the coronal seal and the obturation quality of the root canals were significantly associated with failure of endodontic treatment $[29, \underline{30}]$. Therefore, the diagnostic value of the canal obturation quality evaluation is high. Unfortunately, the evaluation criteria used by different researchers often vary, therefore they are not directly comparable with our results. We assessed the obturation length, obturation homogeneity and coronal seal as separate parameters. The results showed that there was up to $24 \%$ variation between the CBCT and DPR images, in the estimates of canal obturation length as well as obturation material homogeneity. Thus, CBCT-based scorings were up to $23 \%$ higher for complete obturation length, and up to $24 \%$ higher for incomplete obturation of the root canals as compared to the DPR-based scorings.

To conclude the results of the present study, there was not enough support for justification of the CBCT diagnostic priority, in teeth with apical periodontitis. Given the fact that the CBCT technique provides high radiation doses for the patients, the DPR imaging should be the first choice radiography method as an adjunct to clinical acumen in decision-making process before the endodontic treatment. Only in selected cases, when the character of detectable pathology is questioned by DPR and by clinical tests, additional radiographic examination using $\mathrm{CBCT}$ should be considered. These assumptions are in agreement with the position statement of the European Society of Endodontology [31] on the use of CBCT in endodontics.

\section{CONCLUSIONS}

This study concluded that the radiographic assessment of the majority of anatomical and treatment-related parameters could be performed with acceptable reliability and the high level of inter-examiner agreement between three examiners. Cone-beam computed tomography and digital periapical radiographic methods in teeth with apical periodontitis demonstrated similar level of diagnostic capability, although variations related to identification of some treatment-related errors (root perforations, incomplete canal obturations) had been recognized. 


\section{ACKNOWLEDGMENTS AND DISCLOSURE STATEMENTS}

The authors want to thank Per-Erik Isberg (Department of Clinical Sciences Lund, Lund University, Malmö, Sweden) and Irena Nedzelskiene (Clinic of Dental and Oral Pathology, Lithuanian University of Health Sciences, Kaunas, Lithuania) for statistical support.
This research is self-funded and has not received any external financial grants.

The authors deny any conflicts of interest related to this study.

All the authors declared absence of any conflicts of interest.

All authors have contributed significantly and are in agreement with this manuscript.

\section{REFERENCES}

1. Kruse C, Spin-Neto R, Wenzel A, Kirkevang LL. Cone beam computed tomography and periapical lesions: a systematic review analysing studies on diagnostic efficacy by a hierarchical model. Int Endod J. 2015 Sep;48(9):815-28. [Medline: 25283541] [doi: 10.1111/iej.12388]

2. Tsai P, Torabinejad M, Rice D, Azevedo B. Accuracy of cone-beam computed tomography and periapical radiography in detecting small periapical lesions. J Endod. 2012 Jul;38(7):965-70. [Medline: 22703662] [doi: 10.1016/j.joen.2012.03.001]

3. Patel S, Dawood A, Mannocci F, Wilson R, Pitt Ford T. Detection of periapical bone defects in human jaws using cone beam computed tomography and intraoral radiography. Int Endod J. 2009 Jun;42(6):507-15. [Medline: 19298574] [doi: 10.1111/j.1365-2591.2008.01538.x]

4. Patel S, Dawood A, Whaites E, Pitt Ford T. New dimensions in endodontic imaging: part 1. Conventional and alternative radiographic systems. Int Endod J. 2009 Jun;42(6):447-62. [Medline: 19298577] [doi: 10.1111/j.1365-2591.2008.01530.x]

5. Pope O, Sathorn C, Parashos P. A comparative investigation of cone-beam computed tomography and periapical radiography in the diagnosis of a healthy periapex. J Endod. 2014 Mar;40(3):360-5. [Medline: 24565653] [doi: $10.1016 /$ j.joen.2013.10.003]

6. Todd R. Dental imaging - 2D to 3D: a historic, current, and future view of projection radiography. Endod Topics. 2014 Nov;31(1):36-52. [doi: 10.1111/etp.12067]

7. Patel S. New dimensions in endodontic imaging: Part 2. Cone beam computed tomography. Int Endod J. 2009 Jun;42(6):463-75. [Medline: 19298576] [doi: 10.1111/j.1365-2591.2008.01531.x]

8. Lofthag-Hansen S, Huumonen S, Gröndahl K, Gröndahl HG. Limited cone-beam CT and intraoral radiography for the diagnosis of periapical pathology. Oral Surg Oral Med Oral Pathol Oral Radiol Endod. 2007 Jan;103(1):114-9. [Medline: 17178504] [doi: 10.1016/j.tripleo.2006.01.001]

9. Matherne RP, Angelopoulos C, Kulild JC, Tira D. Use of cone-beam computed tomography to identify root canal systems in vitro. J Endod. 2008 Jan;34(1):87-9. [Medline: 18155501] [doi: 10.1016/i.joen.2007.10.016]

10. Pauwels R, Beinsberger J, Collaert B, Theodorakou C, Rogers J, Walker A, Cockmartin L, Bosmans H, Jacobs R, Bogaerts R, Horner K; SEDENTEXCT Project Consortium. Effective dose range for dental cone beam computed tomography scanners. Eur J Radiol. 2012 Feb;81(2):267-71. [Medline: 21196094] [doi: 10.1016/j.ejrad.2010.11.028]

11. Aanenson JW, Till JE, Grogan HA. Understanding and communicating radiation dose and risk from cone beam computed tomography in dentistry. J Prosthet Dent. 2018 Sep;120(3):353-360. [Medline: 29724555] [doi: 10.1016/j.prosdent.2018.01.008]

12. Lorenzoni DC, Bolognese AM, Garib DG, Guedes FR, Sant'anna EF. Cone-beam computed tomography and radiographs in dentistry: aspects related to radiation dose. Int J Dent. 2012;2012:813768. [Medline: 22548064] [PMC free article: 3324904] [doi: 10.1155/2012/813768]

13. Kanagasingam S, Lim CX, Yong CP, Mannocci F, Patel S. Diagnostic accuracy of periapical radiography and cone beam computed tomography in detecting apical periodontitis using histopathological findings as a reference standard. Int Endod J. 2017 May;50(5):417-426. [Medline: 2763209] [doi: 10.1111/iej.12650]

14. Beacham JT, Geist JR, Yu Q, Himel VT, Sabey KA. Accuracy of Cone-beam Computed Tomographic Image Interpretation by Endodontists and Endodontic Residents. J Endod. 2018 Apr;44(4):571-575. [Medline: 29397216] [doi: 10.1016/j.joen.2017.12.012]

15. Durack C, Patel S, Davies J, Wilson R, Mannocci F. Diagnostic accuracy of small volume cone beam computed tomography and intraoral periapical radiography for the detection of simulated external inflammatory root resorption. Int Endod J. 2011 Feb;44(2):136-47. [Medline: 21083575] [doi: 10.1111/j.1365-2591.2010.01819.x]

16. Venskutonis T, Plotino G, Tocci L, Gambarini G, Maminskas J, Juodzbalys G. Periapical and endodontic status scale based on periapical bone lesions and endodontic treatment quality evaluation using cone-beam computed tomography. J Endod. 2015 Feb;41(2):190-6. [Medline: 25498834] [doi: 10.1016/j.joen.2014.10.017] 
17. Patel S, Wilson R, Dawood A, Foschi F, Mannocci F. The detection of periapical pathosis using digital periapical radiography and cone beam computed tomography - part 2: a 1-year post-treatment follow-up. Int Endod J. 2012 Aug;45(8):711-23. [Medline: 22775142] [doi: 10.1111/j.1365-2591.2012.02076.x]

18. Fleiss JL, Levin B, Paik MC. Statistical Methods for Rates and Proportions, 3rd Edition. New York: Wiley, John and Sons, Inc.; 2003 Sep;3:64-85. [doi: 10.1002/0471445428]

19. Landis JR, Koch GG. The measurement of observer agreement for categorical data. Biometrics. 1977 Mar;33(1):159-74. [Medline: 843571] [doi: 10.2307/2529310]

20. Rodríguez G, Abella F, Durán-Sindreu F, Patel S, Roig M. Influence ofCone-beam Computed Tomography in Clinical Decision Making among Specialists. J Endod. 2017 Feb;43(2):194-199. [Medline: 28132707] [doi: 10.1016/j.joen.2016.10.012]

21. Liang YH, Jiang L, Gao XJ, Shemesh H, Wesselink PR, Wu MK. Detection and measurement of artificial periapical lesions by cone-beam computed tomography. Int Endod J. 2014 Apr;47(4):332-8. [Medline: 23815501] [doi: 10.1111/iej.12148]

22. Matherne RP, Angelopoulos C, Kulild JC, Tira D. Use of cone-beam computed tomography to identify root canal systems in vitro. J Endod. 2008 Jan;34(1):87-9. [Medline: 18155501] [doi: 10.1016/j.joen.2007.10.016]

23. Nascimento EHL, Abrahão Elias MR, Vasconcelos VHF, Haiter-Neto F, Mendonça EF, Sousa TO. Ex Vivo Detection of Apical Delta in Premolars: A Comparative Study Using Periapical Radiography, Cone-beam Computed Tomography, and Micro-computed Tomography. J Endod. 2019 May;45(5):549-553. [Medline: 30954279] [doi: 10.1016/j.joen.2019.02.022]

24. Parker JM, Mol A, Rivera EM, Tawil PZ. Cone-beam Computed Tomography Uses in Clinical Endodontics: Observer Variability in Detecting Periapical Lesions. J Endod. 2017 Feb;43(2):184-187. [Medline: 28024758] [doi: 10.1016/j.joen.2016.10.007]

25. Weissman J, Johnson JD, Anderson M, Hollender L, Huson T, Paranjpe A, Patel S, Cohenca N. Association between the Presence of Apical Periodontitis and Clinical Symptoms in Endodontic Patients Using Cone-beam Computed Tomography and Periapical Radiographs. J Endod. 2015 Nov;41(11):1824-9. [Medline: 26349581] [doi: 10.1016/j.joen.2015.06.004]

26. Shemesh H, Cristescu RC, Wesselink PR, Wu MK. The use of cone-beam computed tomography and digital periapical radiographs to diagnose root perforations. J Endod. 2011 Apr;37(4):513-6. [Medline: 21419300] [doi: 10.1016/j.joen.2010.12.003]

27. Spin-Neto R, WenzelA. Patientmovementand motion artefacts in cone beam computed tomography of the dentomaxillofacial region: a systematic literature review. Oral Surg Oral Med Oral Pathol Oral Radiol. 2016 Apr;121(4):425-33. [Medline: 26972541] [doi: 10.1016/j.0000.2015.11.019]

28. Tsesis I, Rosenberg E, Faivishevsky V, Kfir A, Katz M, Rosen E. Prevalence and associated periodontal status of teeth with root perforation: a retrospective study of 2,002 patients' medical records. J Endod. 2010 May;36(5):797-800. [Medline: 20416422] [doi: 10.1016/j.joen.2010.02.012]

29. Segura-Egea JJ, Jiménez-Pinzón A, Poyato-Ferrera M, Velasco-Ortega E, Ríos-Santos JV. Periapical status and quality of root fillings and coronal restorations in an adult Spanish population. Int Endod J. 2004 Aug;37(8):525-30. [Medline: 15230905] [doi: 10.1111/j.1365-2591.2004.00826.x]

30. Tronstad L, Asbjørnsen K, Døving L, Pedersen I, Eriksen HM. Influence of coronal restorations on the periapical health of endodontically treated teeth. Endod Dent Traumatol. 2000 Oct;16(5):218-21. [Medline: 11202885] [doi: 10.1034/j.1600-9657.2000.016005218.x]

31. Patel S, Brown J, Semper M, Abella F, Mannocci F. European Society of Endodontology position statement: Use of cone beam computed tomography in Endodontics: European Society of Endodontology (ESE) developed by. Int Endod J. 2019 Dec;52(12):1675-1678.[Medline: 31301231] [doi: 10.1111/iej.13187]

\section{To cite this article:}

Gudac J, Hellén-Halme K, Venskutonis T, Puisys A, Machiulskiene V.

Comparison of Selected Anatomical and Treatment-related Diagnostic Parameters Estimated by Cone-Beam Computed Tomography and Digital Periapical Radiography in Teeth with Apical Periodontitis

J Oral Maxillofac Res 2020;11(2):e4

URL: http://www.ejomr.org/JOMR/archives/2020/2/e4/v11n2e4.pdf

doi: $10.5037 /$ jomr.2020.11204

Copyright (C) Gudac J, Hellén-Halme K, Venskutonis T, Puisys A, Machiulskiene V. Published in the JOURNAL OF ORAL \& MAXILLOFACIAL RESEARCH (http://www.ejomr.org), 30 June 2020.

This is an open-access article, first published in the JOURNAL OF ORAL \& MAXILLOFACIAL RESEARCH, distributed under the terms of the Creative Commons Attribution-Noncommercial-No Derivative Works 3.0 Unported License, which permits unrestricted non-commercial use, distribution, and reproduction in any medium, provided the original work and is properly cited. The copyright, license information and link to the original publication on (http://www.ejomr.org) must be included. 